recalled unnecessarily. The coincidence between the detection rate of this neonatal screening strategy and the known population incidence of cystic fibrosis is encouraging. To date the strategy has shown a high specificity and sensitivity of screening for cystic fibrosis from analysis of the initially donated blood spot specimen and is highly acceptable to the paediatricians and families using the service. The accurate screening of neonates for cystic fibrosis is consequently closer to being a reality.

1 Crossley JP, Elliot RP, Smith PA. Dried blood spot screening for cystic fibrosis in the newborn. Lancet 1979;ii:472-4.

2 King DN, Heeley AF, Walsh MP, Kuzemko JA. Sensitive trypsin assay for dried blood spot specimens as a screening procedure for early detection of cystic fibrosis. Lancet 1979;ii:1217-9.

3 Hammond K, Naylor E, Wilken B. Screening for cystic fibrosis. In: Therrell $\mathrm{BL}$, ed. Advances in neonatal screening. Amsterdam: Elsevier Science BL, ed. Advances in
Publishers 1987:377-82.

4 Adriaenssens $K$, Janssen $H$, Van Soom $H$. Two tier screen for cystic fibrosis. Lancet 1981;i:833.

5 Wilken B, Brown ARD, Urwin R, Brown DA. Cystic fibrosis screening by dried blood spot trypsin assay: results in 75000 newborn infants. F Pediat dried blood spot

6 Cassio A, Bernardi F, Piazzi S, et al. Neonatal screening for cystic fibrosis by dried blood spot trypsin assay. Acta Paediatr Scand 1984;73:554-8.

7 Ryley HC, Deam SM, Williams J, et al. Neonatal screening for cystic fibrosis in Wales and the West Midlands: 1 . Evaluation of immunoreactive trypsin test. f Clin Pathol 1988;41:726-9.

8 Heeley AF, Heeley ME, King DN, Kuzemko JA, Walch ASP. Screening for cystic fibrosis by dried blood spot trypsin assay. Arch Dis Child 1982;57: 18-21.

9 Wesley AW, Smith PA, Elliott RB. Experience with neonatal screening for cystic fibrosis in New Zealand using measurement of immunoreactive trypsinogen. Aust Paediatr 7 1989:25:151-5.

10 Rock MJ, Mischler EH, Farrell PM, et al. Newborn screening for cystic fibrosis is complicated by age-related decline in immunoreactive trypsinogen levels. Pediatrics 1990;85:1001-7.

11 Pederzini F, Mastella G, Rizzotti P, Zanchetta M. Serum lipase and trypsin in neonatal detection of cystic fibrosis. Lancet 1984;i:959-60.

12 Ad Hoc Committee Task Force on Neonatal Screening, Cystic Fibrosis Foundation. Neonatal screening for cystic fibrosis: position paper. Pediatrics Foundation. Ne

13 Kerem B, Rommens JM, Buchanan JA, et al. Identification of the cystic fibrosis gene: genetic analysis. Science 1989;284: 1073-80.

14 Kerem B, Zielenski J, Markiewicz D, et al. Identification of mutations in regions corresponding to the two putative nucleotide (ATP) binding folds of the cystic fibrosis gene. Proc Natl Acad Sci 1990;87:8447-51.

15 Nelson PV, Carey WF, Morris CP, et al. The frequency of the common $\left(\Delta \mathrm{F}_{\mathrm{s} 0 \mathrm{~s}}\right)$ cystic fibrosis mutation in the Australian population. Med $\mathcal{J}$ Aust 1990;152:328.

16 Gibson LE, Cooke RE. A test for concentration of electrolytes in sweat in cystic fibrosis of the pancreas utilizing pilocarpine by iontophoresis. Pediatrics 1959;23:545-9.

17 Wilken B, Chalmers G. Reduced morbidity in patients with cystic fibrosis detected by neonatal screening. Lancet 1985;ii: 1319-21.

18 Dankert-Roelse JE, Meerman GJ, Martiin A, et al. Survival and clinical outcome in patients with cystic fibrosis, with or without neonatal screening. outcome in patients with cystic

19 Chatfield S, Owen G, Ryley HC, et al. Neonatal screening for cystic fibrosis in Wales and the West Midlands: clinical assessment after five years of

20 Wilken B, Brown ARD. Screening for cystic fibrosis in New South Wales, Australia: evaluation of the results of screening of 400000 babies. In: Therrell BL, ed. Advances in neonatal screening. Amsterdam: Elsevier Science Publishers, 1987:385-90.

21 Bowling FG, Bundesen PG, Brown ARD. A monoclonal antibody based trypsinogen enzyme-immunoassay screening test for cystic fibrosis. In: Therrell BL, ed. Advances in neonatal screening. Amsterdam: Elsevier Science Publishers, 1987:391-2.

22 Diamandis EP. Immunoassays with time-resolved fluorescence spectroscopy: principles and applications. Clin Biochem 1988:21:139-50.

23 Cutting GR, Kasch LM, Rosenstein BJ, et al. A cluster of cystic fibrosis mutations in the first nucleotide-binding fold of the cystic fibrosis conductance regulator protein. Nature 1990;346:366-9.

(Accepted 22 March 1991)
Department of Diabetes, University Hospital, Nottingham NG7 2UH Robert Tattersall, FRCP, professor

Robert Gregory, DM, registrar

Colin Selby, MRCP, registrar David Kerr, DM, registrar Simon Heller, DM, senior registrar

Correspondence and requests for reprints to: Professor Tattersall.

$B M \mathcal{F} 1991 ; 302: 1240-3$

\title{
Course of brittle diabetes: 12 year follow up
}

\author{
Robert Tattersall, Robert Gregory, Colin Selby, David Kerr, Simon Heller
}

Abstract

Objective-To determine the course of brittle diabetes.

Design-12 year follow up of patients identified in 1977-9 as having brittle diabetes; retrospective review of the case notes.

Setting-Nottingham health district.

Subjects-25 brittle diabetic patients were identified in 1979-9; 11 (five men) had three or more admissions with ketoacidosis between June 1977 and 1979 and 14 (eight men) had three or more attendances at the accident and emergency department with hypoglycaemia in 1978. Two controls from our diabetic register were matched to each patient for age, sex, and duration of diabetes.

Main outcome measures-Frequency of ketoacidosis and severe hypoglycaemia in the 12 years after ascertainment; diabetic control and complications in 1988-90; retrospective attribution of the cause of brittleness.

Results - Patients with recurrent ketoacidosis had had a median (range) of 28 (8-67) episodes. One man died of a cerebral tumour but five of the surviving nine patients had not been admitted in the past two years, although diabetic control remained poor (median haemoglobin $A_{1}$ concentration 14\%). Seven patients had pure hypoglycaemic brittleness, and five had also had eight or more admissions with ketoacidosis (mixed brittleness). Two died of uraemia within a year after ascertainment and two others in hypoglycaemic coma seven and 12 years later. Brittle diabetes was in most cases related to a specific situation, usually unhappiness at home or school.

Conclusions-Brittle diabetes is often episodic and almost always related to stressful life circum- stances. Once the underlying cause is removed it tends to improve. Recurrent hypoglycaemic brittleness of psychological origin has a poor prognosis.

\section{Introduction}

In 1977 one of us (RT) suggested a simple definition for a brittle diabetic patient: "the patient whose life is constantly disrupted by episodes of hyper- or hypoglycaemia, whatever their cause." Little is known about the course of brittle diabetes. Most studies have been cross sectional and concentrated on highly selected groups who have reached a specialist centre only because of the strain they place on hospital resources and family stability. We tried to clarify the course by an almost complete 12 year follow up of patients with recurrent ketoacidosis or severe hypoglycaemia from a defined population.

\section{Subjects and methods}

Nottingham has two general hospitals but only one accident and emergency department serving a population of 650000 . When this study started in 1977 the prevalence of diabetes treated with insulin in the catchment area was $3 \cdot 5 / 1000$ population. ${ }^{2}$ Most patients with insulin dependent diabetes in our catchment area attend a clinic at one of the general hospitals, and since 1978 their records have been kept on computer. ${ }^{3}$ Each patient has an annual review which includes height, weight, blood pressure, haemoglobin $A_{1}$ concentration (measured by electroendosmosis ${ }^{4}$ since 1982; normal range $4 \cdot 0-7 \cdot 5 \%$ of total haemoglobin), testing for proteinuria, ophthalmoscopy through dilated pupils, and neurological and vascular examination of the legs. Admissions to both hospitals are recorded by Hospital 
Activity Analysis, which we found previously to record accurately admissions of patients with diabetic ketoacidosis.

We used programme definitions of brittle diabetes that had formed the basis of two previous studies. Between June 1977 and June 1979 we identified all patients admitted to hospital three or more times with diabetic ketoacidosis, ${ }^{5}$ and defined them as having ketoacidotic brittle diabetes. Hypoglycaemic brittle diabetes was diagnosed in patients admitted to the accident and emergency department three or more times with severe hypoglycaemia in $1978 .^{6}$ These two groups of patients were followed up at 12 years.

We selected two control groups from the diabetic register, one group for patients with recurrent hypoglycaemia and one for those with recurrent ketoacidosis. Two controls were matched with each patient for date of birth (within two years), date of diagnosis of diabetes (within two years), and sex. If the control had inadequate records another control was chosen. We also excluded as controls anyone who had been admitted to hospital three times with ketoacidosis in any 24 months or three times with hypoglycaemia in any calendar year since 1979. For each patient and control we recorded age, sex, occupation, marital status, admissions for ketoacidosis, and attendances at the accident and emergency department with hypoglycaemia. At follow up in 1989-90 we recorded insulin dose (units/kg/day), most recent haemoglobin $A_{1}$ concentration, diabetic complications, and other illnesses.

Retrospectively, we classified the cause of brittleness into the following categories adapted from Gill et $a \mathrm{l}$ : therapeutic error (either by doctor or patient), situational, life failure, compulsive aglycosuria, and intercurrent illness (including psychiatric illness).

The numbers of admissions with hypoglycaemia and ketoacidosis in 1988-90 in the brittle and matched control groups were compared by Fisher's exact test.

\section{Results}

\section{RECURRENT KETOACIDOSIS}

Eleven patients (five men) had three or more admissions for ketoacidosis between 1977 and 1979 . One 12 year old girl was lost to follow up in 1982 and was excluded from the analysis and not matched with a control. Of the 10 others, eight had developed diabetes in childhood and two at ages 27 and 40 years (table I). The median number of episodes of ketoacidosis was 28 (range 8-67); six patients (two men) had had more than 20 episodes. By contrast, five $(40 \%)$ had never been admitted for severe hypoglycaemia, and the lifetime average number of admissions with hypoglycaemia was only two per patient.

TABLE I-Details of brittle diabetic patients and matched controls

\begin{tabular}{|c|c|c|c|c|}
\hline & $\begin{array}{c}\text { Recurrent } \\
\text { hypoglycaemia group }\end{array}$ & $\begin{array}{c}\text { Control } \\
\text { group }\end{array}$ & $\begin{array}{c}\text { Recurrent } \\
\text { ketoacidosis group }\end{array}$ & $\begin{array}{l}\text { Control } \\
\text { group }\end{array}$ \\
\hline No of patients (males/females) & $12^{\star}(6 / 6)$ & $24(12 / 12)$ & $10+(5 / 5)$ & $20(10 / 10)$ \\
\hline $\begin{array}{l}\text { Median (range) age at diagnosis of diabetes } \\
\text { (years) } \\
\text { Median (range) duration of diabetes in 1989-90 }\end{array}$ & $12(5-25)$ & $12(10-26)$ & $10(2-40)$ & $10(1 \cdot 6-41)$ \\
\hline (years) & $21(14-45) \ddagger$ & $20(13-46)$ & $19(11-22)$ & $17(11-23)$ \\
\hline Total No of admissions with hypoglycaemia & 237 & 10 & 20 & 22 \\
\hline No of patients admitted with hypoglycaemia & 12 & 8 & 6 & 9 \\
\hline Total No of admissions/patient (range) & 6.40 & $0-2$ & $0-8$ & $0-8$ \\
\hline $\begin{array}{l}\text { No of admissions with hypoglycaemia/year } \\
\text { of diabetes }\end{array}$ & $0 \cdot 83$ & 0.02 & $0 \cdot 12$ & 0.07 \\
\hline Total No of admissions with ketoacidosis & 75 & 11 & 292 & 23 \\
\hline No of patients admitted with ketoacidosis & 8 & 7 & 10 & 11 \\
\hline Lifetime admissions/patient (range) & $0-26$ & $0-2$ & $8-67$ & $0-4$ \\
\hline $\begin{array}{l}\text { No of admissions with ketoacidosis/year } \\
\text { of diabetes } \\
end{array}$ & $0 \cdot 26$ & 0.02 & 1.69 & 0.07 \\
\hline
\end{tabular}

^Excludes two patients who died of uraemia within 18 months.

†Excludes one patient who was lost to follow up in 1980 .

$\ddagger$ Excludes one patient who died in 1982

$\S$ Lifetime total admissions/group total years of diabetes.
One patient, a divorced alcoholic, died in 1990 of a frontal lobe dermoid cyst, and there were no deaths in the control group. Only five patients had been admitted with ketoacidosis in the past two years, but as a group, their diabetic control was unsatisfactory with a median haemoglobin $A_{1}$ concentration of $14.0 \%$ (table II). The prevalence of complications was similar to that in the control group.

In five cases the instability was present for only a few years, and in retrospect this was clearly related to a specific situation, usually unhappiness at home or school. In three others admissions with ketoacidosis were more evenly spread over the 12 years and were accompanied by other social or medical problems (anorexia nervosa and alcoholism). One patient, who had family problems and a personality disorder stopped being admitted with ketoacidosis but was admitted, albeit less frequently, with other medical conditions.

The following examples illustrate the three different patterns.

Case 1-This man had developed diabetes at age 5 and between the ages of 14 and 17 was admitted to hospital 30 times. No cause was found for any of these episodes, recovery was swift, and it became obvious that he enjoyed being in hospital and disliked school and home. After he left school and home in 1979 he was admitted to hospital only twice, once for abdominal pain and once for an insulin overdose after his wife left him. Control of his diabetes was poor (haemoglobin $A_{1}$ concentration $12.5 \%$ ), but his only complication was background retinopathy. In retrospect, his sister, who had developed diabetes a year before his brittleness began, believed that it was deliberately induced to obtain his mother's attention, though he attributed it to a need to escape from his parents' marital disharmony.

Case 2-A mother with six children developed diabetes aged 40 and started insulin four years later because of tablet failure. Between 1977 and 1985 she was admitted 30 times with ketoacidosis, 21 times on a Friday or Saturday coinciding with weekends when her husband came home. She had often been seriously ill when admitted and it was agreed that she should refer herself to the diabetes ward if she needed a rest. After her divorce in 1986 admissions fell from five to two a year and the duration of each admission from an average of five to two days.

Case 3-A daughter of West Indian parents developed diabetes at age 10 . Four years later, during which time she had been admitted to hospital four times with ketoacidosis, she was thought to be seriously depressed. However, her parents refused to allow her to see a psychiatrist. From age 15 to 19 she had 52 admissions with ketoacidosis, took three overdoses of analgesics, performed reasonably well in school examinations, and lost her only confidant at home when her elder brother was sent to prison. She admitted that all her admissions were precipitated by omitting insulin and said several times, "If you send me home, I'll kill myself." Discussion of her problems was repeatedly blocked by her parents' refusal to discuss the situation. After 1982 she trained as a nurse and was admitted once with ketoacidosis, once with hypoglycaemia, and several times with other problems.

\section{RECURRENT HYPOGLYCAEMIA}

Fourteen patients (eight men) were seen in the accident and emergency department three or more times with hypoglycaemia in 1978. Two men with nephropathy died of uraemia within 18 months and were excluded from the analysis and not matched with controls. No patients with recurrent ketoacidosis had had more than eight admissions in their lifetime with hypoglycaemia, but five with recurrent hypoglycaemia 


\begin{tabular}{|c|c|c|c|c|}
\hline & Recurrent hypoglycaemia group & Control group & Recurrent ketoacidosis group & Control group \\
\hline No of patients & 12 & 24 & 10 & 20 \\
\hline No of patients (No of admissions) in past & & & & \\
\hline 2 years with hypoglycaemia & $7(13)$ & $1(1)^{\star}$ & $1(1)$ & $1(2)$ \\
\hline No of patients (No of admissions) in past & & & & \\
\hline 2 years with ketoacidosis & & & $5(9)$ & $1(1) \dagger$ \\
\hline $\begin{array}{l}\text { Median (range) last haemoglobin } A_{1} \\
\text { concentration }(\%)\end{array}$ & $9 \cdot 3(7 \cdot 9-14 \cdot 2)(n=10)$ & $10 \cdot 3(6 \cdot 5-13 \cdot 9)(n=21)$ & $14 \cdot 0(8 \cdot 8-15 \cdot 9)(n=6)$ & $11 \cdot 8(7 \cdot 4-14 \cdot 6)(\mathrm{n}=17)$ \\
\hline Median (range) insulin dose ( $\mathrm{U} / \mathrm{kg} /$ day) & $0.70(0.40-1 \cdot 02)$ & $0.73(0 \cdot 26-1 \cdot 12)$ & $0.95(0.62-2 \cdot 14)$ & $0.90(0.42-1.25)$ \\
\hline No who died & 2 & 1 & 1 & \\
\hline \multicolumn{5}{|l|}{ No $(\%)$ with microvascular complications: } \\
\hline None & $5(42)$ & $8(33)$ & $1(10)$ & $5(25)$ \\
\hline Background retinopathy & $3(25)$ & $10(42)$ & $6(60)$ & $10(50)$ \\
\hline Proliferative retinopathy & $4(33)$ & $6(25)$ & $3(30)$ & $4(20)$ \\
\hline Proteinuria & $1(9)$ & $2(8)$ & $1(10)$ & $2(10)$ \\
\hline No (\%) employed & $9(75)$ & $22(92)$ & $8(80)$ & $19(95)$ \\
\hline No $(\%)$ married & $6(50)$ & $19(79)$ & $4(40)$ & $9(45)$ \\
\hline
\end{tabular}

^Fisher's exact test $\mathrm{p}=0.000175$

†Fisher's exact test $\mathrm{p}=0.000177$.

had had eight or more admissions with ketoacidosis (mixed brittleness; figure).

In seven cases the instability consisted wholly of recurrent hypoglycaemic coma. In a 15 year old girl who, only four years after diabetes was diagnosed, was being treated with $4 \cdot 2 \mathrm{U} / \mathrm{kg} /$ day insulin and having frequent nocturnal fits the cause was clearly iatrogenic. In 1979 her insulin dose was reduced to less than $1 \mathrm{U} / \mathrm{kg} / \mathrm{day}$, and she subsequently remained well. Two patients had personality disorders and three others were addicted to the idea that their urine should always be free of sugar (compulsive aglycosuria) or that their blood sugar concentration should be below $5 \mathrm{mmol} / \mathrm{l}$.

In addition to the two men with renal failure, two women died of hypoglycaemia during the 12 years (table II): one aged 27 with a long history of manipulative behaviour and whose hospital notes weighed $10.2 \mathrm{~kg}$, suffered irreversible brain damage after a deliberate insulin overdose, and the other, a 56 year old woman with severe diabetic complications and a long psychiatric history, was brought to hospital in hypoglycaemic coma and found to be dead on arrival. The

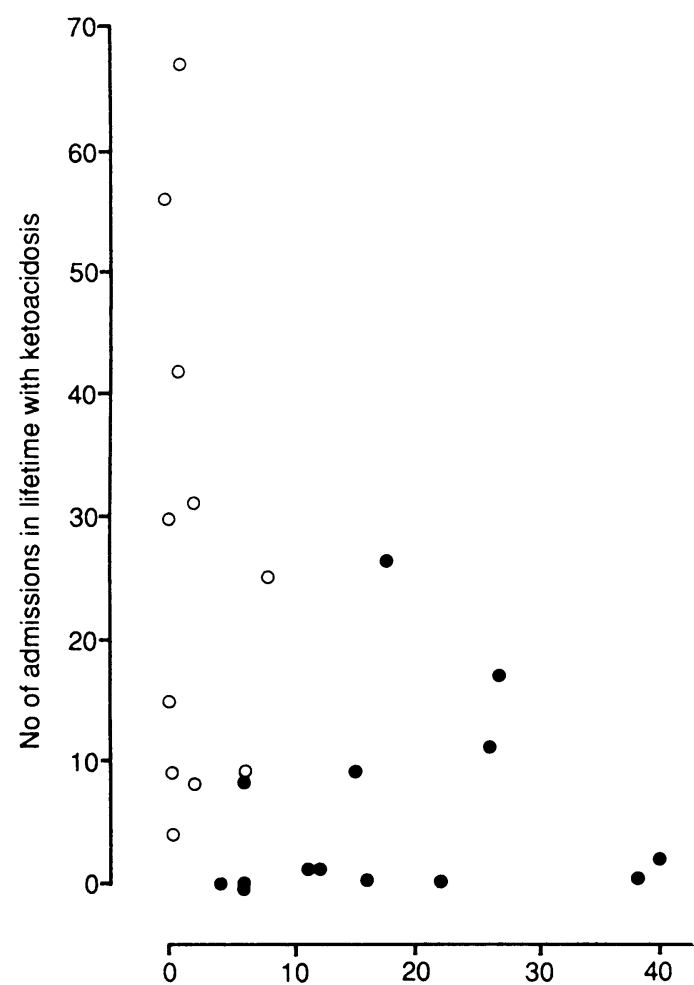

No of admissions in lifetime with hypoglycaemic coma Number of admissions in lifetime with ketoacidosis and hypoglycaemia in 25 patients ascertained to have brittle diabetes in 1977-9. $O=$ Patient with three or more admissions for ketoacidosis between fune 1977 and fune 1979. =Patient with three or more severe hypoglycaemic attacks in 1978 prevalence of diabetic complications in the patients was similar to that in the control group.

\section{Discussion}

The term brittle diabetes is usually credited to Woodyatt, who described "insulin-dependent diabetics whose control is so fragile that they are subject to frequent and precipitous fluctuations between hyperglycaemia and insulin reactions and in whom known causes of instability have been excluded." The definition used in this study is arbitrary but, however defined, the course of brittle diabetes is not well documented. It has been suggested that, because it is rarely reported in people older than 30 it must either resolve or be fatal. ${ }^{9}$ Malins suggested that instability was usually transient ${ }^{10}$ whereas others have regarded it as sufficiently serious to warrant pancreatic transplantation. ${ }^{\prime \prime}$

Our series is a nearly complete 12 year follow up of 25 patients representative of a total community. The number of patients with recurrent hypoglycaemia may have been underestimated because it includes only those who were brought to the accident and emergency department. The degree of underascertainment is unlikely to be great, however, as relatives were rarely provided with glucagon in Nottingham in 1979.

It may seem surprising that about half our patients were men as it is generally thought that brittle diabetes is confined to young women. ${ }^{791213}$ The most probable explanation for this misconception is selection bias due to tertiary referral. In three large cross sectional studies patients were referred from many different centres ${ }^{721:}$ whereas ours came from a clearly defined geographic area. Other community based studies have found men with brittle diabetes: Farberow et al reported 12 uncooperative male veterans aged $30-60$ years with a median of 12 hospital admissions (range 4-20), ${ }^{14}$ and Flexner et al imply an equal sex distribution of their 45 recidivists who were repeatedly admitted to hospital with ketoacidosis. ${ }^{15}$ We had no elderly women in our series, but we recognise them as part of the total picture of brittle diabetes in a community. ${ }^{16}$

It has been suggested that patients with hyper-. glycaemic and hypoglycaemic instability form two more or less distinct groups, ${ }^{77}$ and this is confirmed by the fact that over 12 years only six of our 25 patients had mixed brittleness. We will therefore discuss the two groups separately.

\section{RECURRENT KETOACIDOSIS}

The only other follow up study of patients with recurrent ketoacidosis is a tertiary referral series in which 12 of 13 women had predominantly ketoacidotic brittleness. ${ }^{9}$ At referral these women had spent an average of 12 weeks in hospital during the previous year. During follow up of three to six years one died of 
hypoglycaemia but, in the 12 survivors, disruption of lifestyle lessened greatly, with an average of only 3.5 weeks being spent in hospital during the year of follow up. We also found that ketoacidotic brittle diabetes usually improves with time; half our patients had had no diabetes related admissions in the two years up to 1990 and the other half had only had nine admissions with ketoacidosis. The prevalences of background and proliferative retinopathy and proteinuria were similar in patients and controls.

The causes of recurrent ketoacidosis are varied but include treatment error, intercurrent illness, psychological problems, and insulin resistance syndromes. Many believe that psychological and social factors are the single most important cause, accounting for a third of cases in one series, ${ }^{7} 61 \%$ in another, ${ }^{9}$ and $80 \%$ in a third..$^{12}$ Retrospectively, the cause in $80 \%$ of our patients was thought to be psychosocial problems, including unsatisfactory relations with parents or spouse or unhappiness at school.

We did not use a specific protocol for treating brittle diabetes, but the tendency to become more stable was unlikely to be due to home monitoring of blood glucose concentration, better education, or multiple insulin injections. Neither pumps nor pens have been successful in stabilising or improving the control of adolescent diabetics, ${ }^{1819}$ and Williams and Pickup comment that closely supervised, continuous subcutaneous infusion of insulin failed in all their patients. ${ }^{9}$ Several of our patients had had (largely ineffective) psychiatric intervention, but the main stabilising factor seemed to be removal of the stress, either by leaving home or getting divorced. Two men resembled "uncooperative veterans" 14 in that they had low frustration tolerance and poor impulse control and were alone because of separation or divorce and had poor outside resources with no family support.

\section{RECURRENT HYPOGL YCAEMIA}

Most definitions of brittle diabetes include patients with excessively frequent hypoglycaemia, especially if the cause is obscure. However, it is not easy to define "excessively frequent" as severe attacks occur in $10-25 \%$ of insulin dependent patients in any year. ${ }^{20}$ The main risk factor is previous severe attacks, and the typical patient is well described by Clausen-Sjobom et al. ${ }^{21}$ In their series from a defined area $3 \%$ of patients treated with insulin had had repeated severe and inexplicable attacks. ${ }^{21}$ The sexes were equally represented, but $80 \%$ had had diabetes for over 20 years and three quarters of those with longstanding diabetes had defective counter-regulation. Three of our patients conformed to this stereotype, and all complained of hypoglycaemic unawareness. In six of our patients, however, brittleness began within five years after diagnosis and two of them were strongly suspected of deliberately inducing hypoglycaemia. Deliberate induction of hypoglycaemia has been described by other groups. ${ }^{22} 23$

Four of 14 patients with recurrent hypoglycaemia died during the 12 year follow up; two had renal failure, but two others died as a consequence of hypoglycaemia, almost certainly deliberately induced. In addition, three patients had had epilepsy diagnosed as a result of fits, but in two it had been possible to stop anticonvulsant drugs, suggesting that the hypo- glycaemia had caused the fits. Thus, the prognosis of recurrent hypoglycaemia was not good and was not counterbalanced by a reduction in diabetic complications.

\section{Conclusion}

Only two patients, both with end stage diabetic nephropathy, had an organic cause for brittle diabetes. In the rest instability was due to behavioural or social factors. Admission rates for both groups fell greatly over the 12 years of follow up, and in 1989-90 only one patient from each group would have fulfilled the original inclusion criteria. Nevertheless, admission rates for both hypoglycaemia and ketoacidosis remain significantly higher than those in the control groups. Though no patient in the ketoacidosis group had died as a result of diabetes, two in the recurrent hypoglycaemia group had died of hypoglycaemia. The prevalence of complications in patients with brittle diabetes, whether hypoglycaemic or ketoacidotic, was comparable with that in patients whose diabetes had never been brittle.

The groundwork for this study was laid by Dr Edwin Gale in 1977-9 while he was R D Lawrence Research Fellow of the British Diabetic Association. We thank Pat Lister for typing the manuscript and Simon Allison, William Jeffcoate, and David Hosking for allowing us access to data on their patients.

1 Tattersall R. Brittle diabetes. Clinical Endocrinology and Metabolism 1977;6: 403-19.

2 Hedley AJ, Jones RB, Gale EAM, Tattersall RB. Prevalence of insulin treated diabetes. $B M \mathcal{F}$ 1982;285:509.

3 Jones RB, Hedley AJ, Peacock I, Allison SP, Tattersall RB. A computer assisted register and information system for diabetes. Methods of Information in Medicine. 1983;22:4-14.

4 Ambler J, Janik B, Walker G. Measurement of glycosylated hemoglobin in cellulose acetate membrane by mobile affinity electrophoresis. Clin Chem 1983;29:340-3.

5 Gale EAM, Dornan TL, Tattersall RB. Severely uncontrolled diabetes in the over-fifties. Diabetologia 1981;21:25-8.

6 Potter J, Clarke P, Gale EAM, Dave SH, Tattersall RB. Insulin-induced hypoglycaemia in an accident and emergency department: the tip of an hypoglycaemia in an accident

7 Gill GV, Walford S, Alberti KGMM. Brittle diabetes-present concepts. Diabetologia 1985;28:579-89.

8 Woodyatt RT. Diabetes mellitus. In: Cecil RL, ed. A textbook of medicine. 3rd ed. Philadelphia: WB Saunders, 1934:628.

9 Williams G, Pickup JC. The natural history of brittle diabetes. Diabetes Res 1988;7:13-8.

0 Malins JM. Clinical diabetes mellitus. London: Eyre and Spottiswoode, 1968.

1 University of Michigan Pancreas Transplant Evaluation Committee. Pancreatic transplantation as a treatment for IDDM: proposed candidate criteria before end stage diabetic nephropathy. Diabetes Care 1988;11:669-75.

12 Schade DS, Drumm DA, Duckworth WC, Eaton RP. The etiology of incapacitating brittle diabetes. Diabetes Care 1985;8:12-20.

13 Chapman J, Wright AD, Nattrass M, Fitzgerald MG. Recurrent diabetic ketoacidosis. Diabetic Med 1988-5:659-61.

14 Farberow NL, Darbonne AR, Stein K, Hirsch S. Self-destructive behaviour of unco-operative diabetics. Psychol Rep 1970;27:935-46.

15 Flexner CW, Weiner JP, Saudek CD, Dans PE. Repeated hospitalisation for diabetic ketoacidosis: the game of sartoris. Am I Med 1984;76:691-5.

16 Griffith DNW, Yudkin J. Brittle diabetes in the elderly. Diabetic Med 1989;6:440-3.

17 Tattersall RB. Britule diabetes. BMY 1985;291:55-6.

18 Brink SJ, Stewart C. Insulin pump treatment in insulin-dependent diabetes mellitus: children, adolescents and young adults. FAMA 1986;255:617-21.

19 Hardy KJ, Jones KE, Gill GV. Deterioration in blood glucose control in females with diabetes changed to a basal-bolus regimen using a pen injector. Diabetic Med 1991;8:69-71.

20 Cryer PE, Binder C, Bolli GB, Cherrington AD, Gale EAM, Gerich JE, et al. Conference summary-hypoglycaemia in IDDM. Diabetes 1989;38:1193-9.

21 Clausen-Sjobom N, Adamson U, Lins P-E. The prevalence of impaired glucose counter-regulation during an insulin infusion test in insulin-treated diabetic patients prone to severe hypoglycaemia. Diabetologia 1989;32:81825.

22 O'Brien IAD, Lewin IG, Frier BM, Rodman H, Genuth S, Corrall RJM. Factitious diabetic instability. Diabetic Med 1985;2:392-4.

23 Schulter G, Petersen K-G, Khalaf A-N, Kerp L. Insulin abuse in longstanding IDDM. Diabetes Res Clin Pract 1989;6:145-8.

(Accepted 12 April 1991) 